\title{
ADAPTASI PENDERITA PENYAKIT GINJAL KRONIS DALAM MENGHADAPI PROSES HEMODIALISIS
}

\author{
Yuni Kurniawaty*, Ni Nyoman Wahyu Lestarina* \\ *Stikes Katolik St. Vincentius a Paulo Jalan Jambi No. 12-18 Surabaya \\ orchid_yuna@yahoo.co.id
}

\begin{abstract}
ABSTRAK
Penyakit ginjal kronis atau chronic kidney disease (CKD) terus meningkat jumlahnya di Indonesia sebesar $0,2 \%$. Prevalensi pada laki-laki $(0,3 \%)$ lebih tinggi dari perempuan $(0,2 \%)$. CKD stadium 5 memerlukan terapi pengganti ginjal hemodialisis, dialisis peritoneal dan transplantasi ginjal. Penderita CKD mengalami perubahan fisik, perubahan psikologis, sosial dan ekonomi. Menurut Calista Roy manusia adalah sistem yang holistik dan adaptif dengan menggunakan mekanisme koping yang sudah diidentifikasi. Tujuan penelitian ini untuk mengetahui adaptasi dan respon penderita CKD. Jenis penelitian kualitatif dengan metode fenomenologi. Penelitian ini dilakukan di RS William Booth Surabaya. Penentuan subyek penelitian bersifat snowball. Informan dalam penelitian ini adalah penderita CKD yang menjalani Hemodialisa dan perawat hemodialisa sejumlah 14 orang. Teknik pengumpulan data dilakukan dengan pengumpulan data primer (indepth interview) dan sekunder (rekam medis informan). Metode Penelitian Perbandingan Tetap (Constant Comparative Method). Proses analisis: reduksi, kategorisasi, sintesisasi dan diakhiri dengan menyusun hipotesis kerja. Hasil penelitian penderita CKD mampu beradaptasi dengan penyakitnya dan menjalani proses penatalaksanaan manajemen terapeutik khususnya hemodialisa. Sejauh ini masih terdapat ketidakpatuhan penatalaksanaan manajemen terapeutik khususnya diet makanan dan minuman oleh penderita CKD dalam batasan tertentu selama tubuh mereka mampu menerima asupan tersebut. Terdapat hambatan beradaptasi dengan penyakitnya diantaranya masalah finansial dan dukungan keluarga dirasa kurang oleh penderita CKD.
\end{abstract}

Kata Kunci: adaptasi, penderita CKD, hemodialisa

\begin{abstract}
Chronic kidney disease or chronic kidney disease (CKD) continues to increase in Indonesia by $0.2 \%$. Prevalence in men $(0.3 \%)$ is higher than women $(0.2 \%)$. Stage 5 CKD requires hemodialysis kidney replacement therapy, peritoneal dialysis and kidney transplantation. CKD sufferers experience physical, psychological, social and economic changes. According to Calista Roy, humans are a holistic and adaptive system using coping mechanisms that have been identified. The purpose of this study was to determine the adaptation and response of patients with CKD. This type of qualitative research is the phenomenological method. This research was conducted at the William Booth Hospital in Surabaya. Determination of research subjects is snowball. The informants in this study were CKD sufferers who underwent hemodialysis and a total of 14 hemodialysis nurses. Data collection techniques are done by collecting primary data (indepth interview) and secondary (informant medical records). Constant Comparative Method. The process of analysis: reduction, categorization, synthesis and end with compiling a working hypothesis. The results of the study of patients with CKD are able to adapt to the disease and undergo a therapeutic management process, especially hemodialysis. So far there are still non-compliance management of therapeutic management, especially food and beverage diets by CKD sufferers within certain limits as long as their bodies are able to receive such intake. There are obstacles to adapting to the disease including financial problems and family support felt lacking by people with CKD.
\end{abstract}

Keywords: adaptation, patients with CKD, hemodialysis 


\section{PENDAHULUAN}

Penyakit tidak menular (PTM) di Indonesia merupakan penyakit kronis yang tidak ditularkan dari orang ke orang. Penyakit ginjal kronis atau chronic kidney disease (CKD) salah satunya. Data kasus CKD di Indonesia sebesar 0,2\%(Badan Penelitian dan Pengembangan Kesehatan (BPPK) Kemenkes RI, 2013). Di Jawa Timur prevalensi penyakit CKD meningkat seiring dengan bertambahnya umur. Prevalensi pada laki-laki $(0,3 \%)$ lebih tinggi dari perempuan $(02 \%)$, prevalensi lebih tinggi pada masyarakat pedesaan $(0,3 \%)$, tidak bersekolah $(0,4 \%)$, pekerjaan wiraswasta, petani/nelayan/buruh $\quad(0,3 \%)$ (Badan Penelitian dan Pengembangan Kesehatan (BPPK) Kemenkes RI, 2013). Insiden CKD dan stadium akhir penyakit ginjal (ESRD) terjadi secara signifikan pada orang berusia 65 dan 65 tahun ke atas (USRDS, 2008 dalam (LeMone, Burke and Bauldoff, 2016).

Banyak penyebab CKD, ditandai dengan kerusakan ginjal selama tiga bulan atau lebih dan tingkat fungsi ginjal (National Kidney Foundation/NKF, 2002 dalam(LeMone, Burke and Bauldoff, 2016)). Pada akhirnya ginjal tidak dapat mengekeskresikan sisa metabolik dan mengatur keseimbangan cairan dan elektrolit secara adekuat, kondisi yang disebut sebagai gagal ginjal (ESRD), tahap akhir CKD(LeMone, Burke and Bauldoff, 2016). CKD stadium 5 atau ESRD memerlukan terapi pengganti ginjal yaitu hemodialisis, dialisis peritoneal dan transplantasi ginjal. Hemodialisis adalah terapi pengganti fungsi ginjal yang menggunakan alat khusus dengan tujuan mengeluarkan toksik uremik dan mengatur cairan elektrolit tubuh(Kementrian Kesehatan RI Pusat Data dan Informasi, 2017). Hemodialisis juga memiliki efek samping yang harus dialami oleh pasien seperti hipotensi, kram otot, mual-muntah, sakit kepala dan sakit dada.

Pasien CKD selain mengalami perubahan fisik, juga mengalami perubahan psikologis, sosial dan ekonomi. Hal ini sesuai dengan teori Roy yaitu manusia adalah sistem yang holistik dan adaptif (Alligood, 2014b). Pasien CKD yang menjalani hemodialisis akan terstimulus untuk mengalami stress. Manusia adalah sistem yang terbuka(Alligood, 2014b) sehingga dalam hidupnya akan menerima stimulus baik dari dalam diri sendiri maupun dari lingkungan. Seseorang akan mampu beradaptasi bila seseorang berespon secara positif terhadap perubahan yang terjadi (Alligood, 2014b). Pasien CKD yang menjalani hemodialisis memerlukan dukungan dari semua pihak. Pasien dengan CKD yang menjalani hemodialisis harus mampu berpikir positif terhadap keadaan sakitnya dan proses hemodialisis yang sedang dijalani sebagai upaya untuk mengoptimalkan fungsi kerja ginjal. Realitas seringkali seseorang memiliki pola pikir yang berbeda. Seseorang bisa saja berpikir negatif sehingga tidak mmpu beradaptasi dengan keadaan yang sedang dialaminya. Mengamati dan melihat peristiwa yang terjadi ini, peneliti ingin mengetahui bagaimana adaptasi dan respon penderita CKD yang sedang menjalani hemodialisis di Rumah Sakit William Booth Surabaya dengan pendekatan Calista Roy.

\section{BAHAN DAN METODE}

Penelitian ini merupakan jenis penelitian kualitatif dengan metode fenomenologi. Fenomenologi diartikan sebagai penelitian terdisiplin tentang kesadaran dari perspektif pertama seseorang atau pengalaman subyektif dari berbagai jenis dan tipe subyek yang ditemui (Moleong, 2014). Pengenalan terhadap penderita CKD yang menjalani hemodialisa mempunyai peranan dalam proses keperawatan penderita CKD selama masa hidupnya dilihat melalui adaptasi model Calista Roy. Serta menemukan bagaimana tanggapan perawat hemodialisa terhadap penderita CKD yang menjalani hemodialisa di RS William Booth Surabaya.

Penelitian kualitatif merupakan penelitian yang menghasilkan data deskriptif mengenai kata - kata lisan maupun tertulis dan tingkah lahu yang dapat diamati dari orang - orang yang diteliti. Laporan berisi amatan berbagai kejadian dan interaki yang diamati langsung oleh penulis dari tempat kejadian yang terlibat dari secara partisipatif di dalam obeservasinya. Tujuan akhir tulisan kualitatif adalah memahami apa yang dipelajari dari perspektif kejadian itu sendiri. Penelitian ini menggunakan pendekatan fenomenologi agar dapat menemukan makna dari usaha penderita CKD yang menjalani hemodialisa untuk mampu beradaptasi 
dengan keadaan yang sedang dihadapi dalam kehidupannya yaitu harus menjalani hemodialisa untuk dapat mempertahankan kualitas hidupnya tetap baik. Serta melihat kebermaknaan perawat hemodialisa yang bertugas di ruang hemodialisa di RS William Booth Surabaya.

\section{Lokasi Penelitian}

Penelitian ini dilakukan di Rumah Sakit William Booth Surabaya yang merupakan salah satu rumah sakit swasta di Surabaya yang menerima layanan BPJS. Layanan di ruang hemodialisa juga merupakan salah satu unit yang menerima pasien BPJS. Sebagian besar pasien CKD yang menjalani hemodialisa di tempat ini mendapatkan fasilitas dari BPJS. Ruang hemodialisa yang dimiliki RS William Booth Surabaya memiliki kapasitas 14 unit alat hemodialisa masing-masing unit dilengkapi dengan satu tempat tidur, meja dan kursi untuk keluarga yang menunggu saat pasien menjalani hemodialisa. Hemodialisa atau cuci darah dilakukan dua seri dalam sehari yaitu pagi dimulai pada jam $08.00-12.00$ WIB pada sore hari jam 13.00 - 17.00 WIB. Setiap seri pelaksanaan hemodialisa berlangsung selama kurang lebih $4-5$ jam. Rata rata pasien CKD menjalani hemodialisa dengan frekuensi 2-3 kali dalam seminggu. Melihat intensitas hemodialisa para penderita CKD di ruang hemodialisa yang cukup sering sehingga relasi antara pasien dengan perawat sangat akrab seolah seperti keluarga sendiri.

\section{Subyek Penelitian}

Penentuan subyek penelitian bersifat snowball, peneliti menentukan informan kunci sehingga dari informan kunci ini peneliti memiliki gambaran untuk menentukan orang-orang yang dapat dijadikan sebagai informan sesuai topik penelitian. Informan dalam penelitian ini adalah penderita CKD yang menjalani Hemodialisis sejumlah 12 orang.

\section{Deskriptif Informan Penelitian}

Pada penelitian ini peneliti menjamin kerahasiaan identitas dari informan, sehingga peneliti hanya menjelaskan bagaimana latar belakang dari informan tanpa menyebutkan identitas. Peneliti melakukan wawancara mendalam kepada informan yaitu perawat hemodialisa dan penderita penyakit ginjal kronis atau cronic kidney deases yang selanjutnya disebut CKD. Adapun informan dalam penelitian ini berjumlah 14 sebagai berikut:

1) Informan $\mathrm{CA}$

CA merupakan informan kunci yang menentukan informan - informan lainnya. Penderita CKD berjenis kelamin laki - laki usia 24 tahun. Sudah 4 tahun terdiagnosis CKD dan menjalani hemidialisa. Saat ini disarankan hemodialisa 2 kali seminggu.

2) Informan $Y N$

YN adalah kepala ruangan hemodialisa RS William Booth yang berusia 39 tahun. Menjadi perawat di ruang hemodialisa sejak tahun 2015 .

3) Informan LS

LS merupakan perawat senior yang bekerja di ruang hemodialisa RS William Booth berusia 53 tahun. YN mulai bekerja di RS William Booth sejak usia 22 tahun.

4) Informan $C T$

Penderita CKD berjenis kelamin laki laki usia 56,5 tahun. Terdiagnosa CKD sejak usia 54 tahun. Mengalami sakit CKD sudah 2,5 tahun. Saat ini disarankan dokter hemodialisis 3 kali seminggu.

5) Informan $\mathrm{HY}$

Penderita CKD berjenis kelamin perempuan usia 62 tahun, sudah 4,5 tahun terdiagnosis dan menjalani hemodialisa.

6) Informan $\mathrm{AB}$

Penderita CKD berjenis kelamin laki laki usia 50 tahun. Sudah 4 tahun terdiagnosa CKD dan menjalani hemodialisa 2 kali seminggu.

7) Informan $\mathrm{KJ}$

Penderita CKD berjenis kelamin laki laki berusia 49 tahun. Saat ini disarankan untuk hemodialisa 2 kali seminggu.

8) Informan ED

Penderita CKD usia 59 tahun sudah 4 tahun terdiagnosa CDK dan menjalani hemodialisa 2 kali seminggu.

9) Informan $\mathrm{VH}$

Penderita CKD berjenis kelamin laki laki usi 43 tahun. Sudah 11 tahun terdiagnosa CKD dan menjalani hemodialisa 2 kali seminggu.

10) Informan PT 
Penderita CKD berjenis kelamin laki laki berusia 69 tahun. Saat ini disarankan hemodialisa 2 kali smeinggu.

11) Informan DJ

Penderita CKD berjenis kelamin laki laki sudah terdiagnosa CKD sejak 25 tahun lalu. Saat ini usia 94 tahun.

12) Informan MY

Penderita CKD berjenis kelamin perempuan usia 40 tahun. sudah terdiagnosa CKD sejak 10 tahun lalu

13) Informan $\mathrm{NN}$

Penderita CKD berjenis kelamin perempuan usia 56 tahun.

14) Informan RL

Penderita CKD jenis kelamin perempuan usia 69 tahun. Saat ini melakukan hemodialisa 2 kali seminggu.

\section{Teknik Pengumpulan Data}

Teknik pengumpulan data dalam penelitian ini dilakukan dengan dua acara yakni pengumpulan data secara primer dan data sekunder. Data primer diperoleh melalui wawancara mendalam (indepth interview) menggunakan pedoman wawancara terhadap beberapa informan. Data sekunder diperoleh melalui dokumen rekam medis informan (Moleong, 2014). Wawancara mendalam dilakukan dengan informan kunci (key informants) dan subyek penelitian. informan kunci adalah orang-orang yang karena pengatauannya yang luas dan mendalam tentang komunitasnya (atau orang luar yang lama bekerja dengan suatu komunitas) dapat memberikan data yang berharga. Satu teknik yang juga amat berguna adalah pengumpulan riwayat hidup (Sugiyono, 2016; Suyanto, et.al., 2011).

\section{Teknik Analisa Data}

Analisis data menurut Patton (1980) dalam (Moleong, 2014) adalah proses mengatur urutan data, mengorganisasikannya ke dalam suatu pola, kategori dan satuan uraian dasar. Ia membedakan dengan penafsiran, yaitu memberikan arti yang signifikan terhadap hasil analisis, menjelaskan pola uraian dan mencari hubungan di antara dimensi - dimensi uraian(Streubert and Carpenter, 2011). Dalam penelitian ini menggunakan Metode Penelitian Perbandingan Tetap (Constant Comparative Method). Menurut Glaser \& Strauss dalam (Moleong, 2014) Metode
Penelitian Perbandingan Tetap (Constant Comparative Method) merupakan analisis data secara tetap membandingkan satu datum dengan datum lain dan kemudian secara tetap membandingkan kategori dengan kategori lainnya. Secara umum proses analisis datanya mencakup: reduksi data, kategorisasi data, sintesisasi dan diakhiri dengan menyusun hipotesis kerja.

\section{1) Reduksi Data}

Identifikasi satuan (unit). Pada mulanya diidentifikasikan adanya satuan yaitu bagian terkecil yang ditemukan dalam data yang memiliki makna bila dikaitkan dengan fokus dan masalah penelitian (Moleong, 2014). Sesudah satuan diperoleh, langkah berikutnya adalah membuat koding. Membuat koding berarti memberikan kode pada setiap 'satuan' agar supaya tetap dapat ditelusuri data/satuannya berasal dari sumber mana (Moleong, 2014). Dalam penelitian ini melakuka reduksi data pada data wawancara yang sudah diubah dalam bentuk trasnkirp.

\section{2) Kategorisasi data}

Menyusun kategori. Kategorisasi adalah upaya memilah - milah setiap satuan ke dalam bagian - bagian yang memiliki kesamaan. Setiap kategori diberi nama yang disebut 'label' (Moleong, 2014). Pemberian label pada setiap kategori yang sudah ditemukan pada proses pengolahan data.

\section{3) Sintesisasi Data}

Mensintesiskan berarti mencari kaitan antara suatu kategori dengan kategori lainnya. Kaitan satu kategori dengan kategori lainnya diberi nama atau label lagi (Moleong, 2014). Mencari kaitan antara satu kategori dengan kategori lain hingga memunculkan pemaknaan dalam penelitian.

\section{4) Hipotesis kerja}

Menyusun hipotesis kerja, hal ini dilakukan dengan jalan merumuskan suatu pernyataan yang proposional. Hipotesis kerja ini sudah merupakan substantive (yaitu teori yang berasal dan masih terkait dengan data) (Moleong, 2014). 
Menyusun hipotesis kerja yang berasal dari dan terkait dengan data penelitian.

\section{HASIL}

Deskriptif Informan Penelitian

Pada penelitian ini peneliti menjamin kerahasiaan identitas dari informan, sehingga peneliti hanya menjelaskan bagaimana latar belakang dari informan tanpa menyebutkan identitas. Peneliti melakukan wawancara mendalam kepada informan yaitu penderita penyakit ginjal kronis atau cronic kidney deases yang selanjutnya disebut CKD. Adapun informan dalam penelitian ini berjumlah 14 sebagai berikut:

1. Informan CA

CA merupakan informan kunci yang menentukan informan - informan lainnya. Penderita CKD berjenis kelamin laki - laki usia 24 tahun. Sudah 4 tahun terdiagnosis CKD dan menjalani hemidialisa. Saat ini disarankan hemodialisa 2 kali seminggu.

2. Informan $\mathrm{YN}$

YN adalah kepala ruangan hemodialisa RS William Booth yang berusia 39 tahun. Menjadi perawat di ruang hemodialisa sejak tahun 2015.

3. Informan LS

LS merupakan perawat senior yang bekerja di ruang hemodialisa RS William Booth berusia 53 tahun. YN mulai bekerja di RS William Booth sejak usia 22 tahun.

4. Informan CT

Penderita CKD berjenis kelamin laki laki usia 56,5 tahun. Terdiagnosa CKD sejak usia 54 tahun. Mengalami sakit CKD sudah 2,5 tahun. Saat ini disarankan dokter hemodialisis 3 kali seminggu.

5. Informan $\mathrm{HY}$

seminggu.
Penderita CKD berjenis kelamin perempuan usia 62 tahun, sudah 4,5 tahun terdiagnosis dan menjalani hemodialisa.

6. Informan $\mathrm{AB}$

Penderita CKD berjenis kelamin laki laki usia 50 tahun. Sudah 4 tahun terdiagnosa CKD dan menjalani hemodialisa 2 kali seminggu.

7. Informan $\mathrm{KJ}$

Penderita CKD berjenis kelamin laki laki berusia 49 tahun. Saat ini disarankan untuk hemodialisa 2 kali seminggu.

8. Informan ED

Penderita CKD usia 59 tahun sudah 4 tahun terdiagnosa CDK dan menjalani hemodialisa 2 kali seminggu.

9. Informan $\mathrm{VH}$

Penderita CKD berjenis kelamin laki laki usi 43 tahun. Sudah 11 tahun terdiagnosa CKD dan menjalani hemodialisa 2 kali seminggu.

10. Informan PT

Penderita CKD berjenis kelamin laki laki berusia 69 tahun. Saat ini disarankan hemodialisa 2 kali smeinggu.

11. Informan DJ

Penderita CKD berjenis kelamin laki laki berusia 49 tahun, sudah terdiagnosa CKD sejak 25 tahun lalu.

12. Informan MY

Penderita CKD berjenis kelamin perempuan usia 40 tahun. sudah terdiagnosa CKD sejak 10 tahun lalu

13. Informan $\mathrm{NN}$

Penderita CKD berjenis kelamin perempuan usia 56 tahun.

14. Informan RL

Penderita CKD jenis kelamin perempuan usia 69 tahun. Saat ini melakukan hemodialisa 2 kali. 
Tabel 1. Matrik Adaptasi Penderita CKD yang Menjalani Hemodialisa

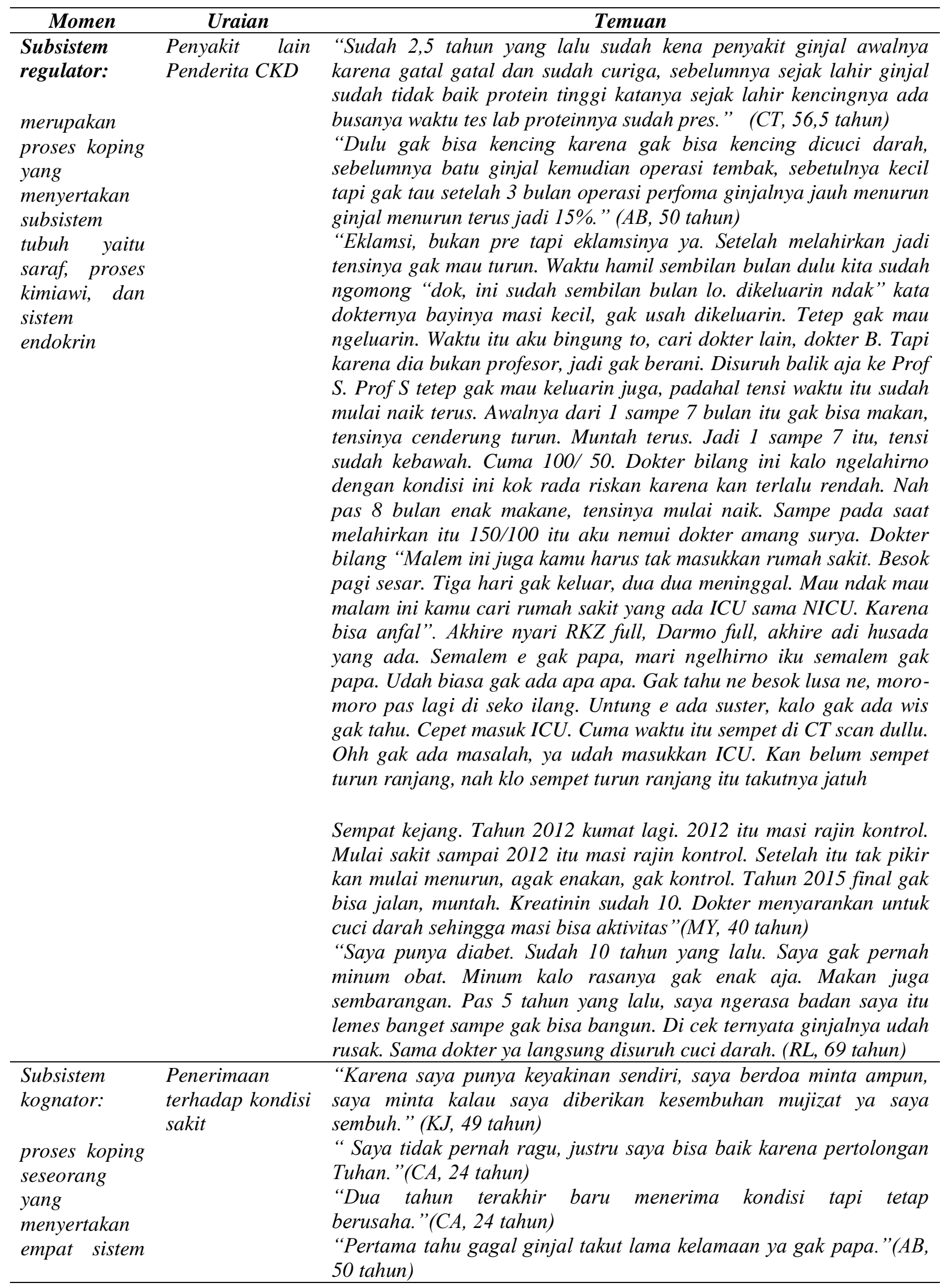




pengetahuan
dan emosi:
pengolahan
persepsi dan
informasi,
pembelajaran,
pertimbangan,
dan emosi

pengetahuan

dan emosi.

pengolahan

persepsi dan

informasi

pertimbangan,

dan emosi
"Waktu divonis gagal ginjal ya takut gak tau obatnya dijalani aja, gak tau penyakit apa itu, sekarang sudah dikasih tau ya dijalani aja seperti orang sehat. Melihat banyak orang yang lebih parah, banyak teman teman yang sudah berpulang, ya Allah terimakasih sudah dikasih umur."(HY, 62 tahun)

"makanya waktu saya ketahuan di tiga koma enam aja sudah hancur tujuh puluh lima persen. Ya sudah"(VH, 43 tahun)

"Bisa adaptasi ya 2 tahunan. Saya ini terlalu bebas minumnya saat itu." (ED, 59 tahun)

"dulu gak tahu. Masih muda sekali saya dan informasi itu gak secanggih sekarang. ngak pernah nyari lagi. Mau dicari apa lagi, wong informasinya sudah mentok itu aja" (DJ, 49 tahun)

"Wis mau ndak mau ya harus cuci darah"(MY, 40 tahun)

"Waktu saya disuruh cuci darah ya saya bilang waduh uang darimana wong istri saya cuman pembantu. Saya bilang gak usah cuci darah di rumah aja. Saya gak punya apa apa. Semua ditanggung dengan BPJS. Cuma ya berdoa saja."(KJ, 49 tahun)

a. Biaya ya cari cari sendiri kadang kalau obat disuruh beli gak bisa ya gak beli saya.

b. Jadi 2 bulan sekali masuk RS risiko karena HB turun gak min obat gak bisa beli. Ya sudah risiko sampe sekarang.

c. Kalau memang begini keadaan saya ya bagaimana.

d. Makanan masak sendiri, kacang kacangan gak boleh, cambah gak boleh, sayur hijau gak boleh, yg boleh papaya sama apel, yang lainnya gak boleh

e. Dulu creatinine 14 sekarang gak tau. Saya lain lainnya bagus fosfor bagus, HB yang turun jarang suntikan untuk penambah $\mathrm{Hb}$ jarang beli karena gak punya uang.

f. Kalau jalan capek ya duduk.'cuman bisa berdoa saja bisanya."(KJ, 49 tahun)

ya dijalanin aja mbak keadaan sekarang ini. Saya pasrah sekarang mbak." (NN, 56 tahun)

"ya pasrah mbak. Mau diapain lagi." (RL, 69 tahun)

Sisi ekonomi "Biaya ya cari cari sendiri kadang kalau obat disuruh beli gak bisa menjadi alasan ya gak beli saya.

melakukan

intervensi medis ." (KJ, 49 tahun)

"mau tidak mau melakukan cuci darah, terkecuali kalau cuci darah membayar mungkin saya angkat tangan saya pasrah aja, syukur anak ada kerja bisa bantu bantu."(CT, 56,5 tahun)

“. Saya untuk kesehatan jujur ya untuk orang tua saya kalo itu untuk kesehatan semuanya dibayar."(CA, 24 tahun)

"Apalagi sekarang ada BPJS. Agak bisa bernafas lega. Dulu kan saya bayar sendiri." (DJ, 49 tahun)

Ketidakpatuhan "Ada pantangannya gak boleh makan ini itu, trus saya pernah nurut penatalaksanaan tenaga saya gak ada saya ngedrop saya, akhirnya saya makan semua manajemen tp gakbanyak. Dulu saya $90 \mathrm{~kb}$ sekarang $73 \mathrm{~kg}$.” (ED, 59 tahun)

CKD "Di rumah juga gak ada pantangan tapi gak banyak, kalau HD ya makannya agak banyak.

."(AB, 50 tahun $)$

"Kadang grup nya mereka itu salah sebenarnya, sembarang dimakan yang diucapkan itu salah."(YN, 39 tahun) 


\begin{tabular}{ll}
\hline Dukungan & "Kalo gak ada dukungan dari keluarga ya loyo"(PT, 69 tahun) \\
keluarga & "mama yang paling gak bisa nerima. Suamiku yang sekarang ini \\
& suami nyambung. Suami aku yang dulu gak terlalu mendampingi. \\
Aku masuk rumah sakit sendiri, pulang sendiri. Tapi ya saya mikir \\
anak, ya semangatnya karena anak. Tapi kalo lagi jenuh ya, kan \\
manusia ada jenuhnya. Justru dari mama kurang terlalu suport ya. \\
Dari temen- temen SD sampe SMA yang sering nanya kabar. Sering \\
kumpul- kumpul."(MY, 40 tahun) \\
"Jadi suami trus yang dampingi sekarang." (NN, 56 tahun) \\
\hline
\end{tabular}

Tabel Matriks adaptasi dibuat saat melakukan proses analisis data dari informan melalui wawancara mendalam. Tabel ini mempermudah proses analisis data pada tahapan ketegorisasi data. Saat kategori data ditemukan beberapa data yang memiliki kesamaan dari beberapa data dari informan. 


\section{PEMBAHASAN}

Proses seseorang dalam beradaptasi menerima kondisi yang sedang dijalani merupakan proses yang sangat personal. Pada dasarnya masing masing individu memiliki mekanisme koping yang berbeda beda bergantung pada banyak hal yang dialami dan yang ada di sekitar mereka. Penderita CKD yang sedang menjalani hemodialisa sebagai satu-satunya cara agar para penderita CKD ini tetap memiliki kualitas hidup karena hemodialisa merupakan pengganti organ ginjal para penderita CKD yang sudah tidak berfungsi melakukan tugasnya dalam tubuh uaitu untuk melakukan filtrasi, absrobsi, reabsorbsi dan sekresi. Keharusan para penderita CKD untuk melakukan hemodialisa seringkali menjadi beban bagi para penderita CKD itu sendiri. Tidak dapat dipungkiri penderita CKD masih belum bisa menerima keadaan diirnya menerima penyakit terminal meskipun sudah melalui proses edukasi dari dokter maupun perawat dan tenaga kesehatan lainnya, penderita CKD tetap saja mengharapkan kesembuhan dalam proses pengobatannya. Jadi proses hemodialisa pada penderita CKD merupakan tindakan medis yang dilakukan untuk mempertahankan kualitas hidup penderita CKD dan bukan untuk penyembuhan penderita CKD.

Pada penelitian ini melihat bahwa penderita CKD yang menjalani hemodialisa akan mengalami proses adaptasi dalam penerimaan kondisi sakit terminal yang mereka hadapi. Calista Roy menyatakan bahwa proses kontrol manusia sebagai suatu sistem adaptasi adalah mekanisme koping yang telah diidentifikasi yaitu: subsistem regulator dan subsistem kognator. Regulator subsistem merupakan proses koping yang menyertakan subsistem tubuh yaitu saraf, proses kimiawi, dan sistem endokrin. Kognator subsistem merupakan proses koping seseorang yang menyertakan empat sistem pengetahuan dan emosi: pengolahan persepsi dan informasi, pembelajaran, pertimbangan, dan emosi. Regulator dan kognator adalah digambarkan sebagai aksi dalam hubunganya terhadap empat efektor cara adaptasi yaitu: fungsi fisiologis, konsep diri, fungsi peran dan interdependensi.

\section{Subsistem regulator}

Pada penelitian ini ditemukan beberapa pemaknaan yang didapatkan dari wawancara informan secara langsung.

\section{Faktor Penyakit}

Pemaknaan penderita CKD dalam menghadapi sakitnya saat ini mereka menyadari sepenuhnya atas risiko atau dampak yang akan dialami saat mereka mengetahui menderita suatu penyakit seperti Diabetes Mellitus (DM) atau Hipertensi (HT) dalam beberapa tahun kemudian apabila mereka tidak dengan sungguh sungguh melakukan pengobatan dengan cara rajin kontrol dan berusaha mengikuti semua advis dari dokter, maka mereka akan masuk dalam kondisi komplikasi kerusakan organ lain salah satunya ginjal. Pemahaman penderita ini diungkapkan seperti di bawah ini:

"saya punya diabet. Sudah 10 tahun yang lalu. Saya gak pernah minum obat. Minum kalo rasanya gak enak aja. Makan juga sembarangan. Pas 5 tahun yang lalu, saya ngerasa badan saya itu lemes banget sampe gak bisa bangun. Di cek ternyata ginjalnya udah rusak. Sama dokter ya langsung disuruh cuci darah.” (RL, 69 tahun)

Pernyataan yang berbeda dari informan lain menyatakan penyakitnya CKD didapat bukan dari penyakit sebelumnya seperti DM atau HT tetapi dari eklamsi yang dialaminya saat sedang hamil yang berdampak beberapa tahun setelah kelahiran anaknya mengalami kerusakan ginjal hingga divonis CKD oleh dokter dan disarankan untuk menjalani hemodialisa seperti pernyataan di bawah ini.

"Eklamsi, bukan pre tapi eklamsinya ya. Setelah melahirkan jadi tensinya gak mau turun. Waktu hamil sembilan bulan dulu kita sudah ngomong " dok, ini sudah sembilan bulan lo.. dikeluarin ndak" kata dokternya bayinya masi kecil, gak usah dikeluarin. Tetep gak mau ngeluarin. Waktu itu aku bingung to, cari dokter lain, dokter B. Tapi karena dia bukan profesor, jadi gak berani. Disuruh balik aja ke Prof $S$. Prof $S$ tetep gak mau keluarin juga, padahal tensi waktu itu sudah mulai naik terus. Awalnya dari 1 sampe 7 bulan itu gak bisa makan, tensinya cenderung turun. Muntah terus. 
Jadi 1 sampe 7 itu, tensi sudah kebawah. Cuma 100/ 50. Dokter bilang ini kalo ngelahirno dengan kondisi ini kok rada riskan karena kan terlalu rendah. Nah pas 8 bulan enak makane, tensinya mulai naik. Sampe pada saat melahirkan itu 150/100 itu aku nemui dokter amang surya. Dokter bilang "Malem ini juga kamu harus tak masukkan rumah sakit. Besok pagi sesar. Tiga hari gak keluar, dua dua meninggal. Mau ndak mau malam ini kamu cari rumah sakit yang ada ICU sama NICU. Karena bisa anfal". Akhire nyari RKZ full, Darmo full, akhire adi husada yang ada. Semalem e gak papa, mari ngelhirno iku semalem gak papa. Udah biasa gak ada apa apa. Gak tahu ne besok lusa ne, moro- moro pas lagi di seko ilang. Untung e ada suster, kalo gak ada wis gak tahu. Cepet masuk ICU. Cuma waktu itu sempet di CT scan dullu. Ohh gak ada masalah, ya udah masukkan ICU. Kan belum sempet turun ranjang, nah klo sempet turun ranjang itu takutnya jatuh. Sempat kejang. Tahun 2012 kumat lagi. 2012 itu masi rajin kontrol. Mulai sakit sampai 2012 itu masi rajin kontrol. Setelah itu tak pikir kan mulai menurun, agak enakan, gak kontrol. Tahun 2015 final gak bisa jalan, muntah. Kreatinin sudah 10. Dokter menyarankan untuk cuci darah sehingga masi bisa aktivitas"(MY, 40 tahun)

\section{Subsistem kognator}

Mekanisme koping penderita CKD melibatkan beberapa sistem pengetahuan dan emosi: pengolahan persepsi dan informasi, pembelajaran, pertimbangan dan emosi hal ini oleh Calista Roy disebut dengan subsistem kognator. Sedangkan Regulator dan kognator adalah digambarkan sebagai aksi dalam hubunganya terhadap empat efektor cara adaptasi yaitu: fungsi fisiologis, konsep diri, fungsi peran dan interdependensi.

\section{Menerima Kondisi Sakit}

Mekanisme koping merupakan suatu mekanisme pertahanan diri individu dalam menghadapi suatu masalah untuk melindungi diri. Pemaknaan penderita CKD yang sedang menjalani proses hemodialisa pada penelitian ini memiliki keyakinan bahwa apa yang sedang dihadapi saat ini termasuk penyakit
CKD yang merupakan penyakit terminal tidak lepas dari atas ijin yang Empunya kehidupan itu sendiri yaitu Tuhan yang menciptakan manusia. Pemaknaan yang dimiliki penderita CKD ini melalui proses dimulai dari vonis dokter bahwa mereka mengalami kerusakan ginjal dan harus melakukan cuci darah untuk menggantikan fungsi ginjal kemudian proses penjelasan dokter dan tenaga kesehatan lain seperti perawat tentang penyakit dan intervensi medis yang harus dijalani sampai dengan proses penderita untuk memahami segala bentuk informasi bahkan mencoba beradaptasi dengan tindakan hemodialisa yang harus dilakukan secara rutin dan memerlukan waktu dan biaya. Maka dengan keyakinan penuh bahwa akan ada mujizat yang diberikan kepadanya apabila ia meminta pemulihan untuk kesembuhannya seperti yang diungkapkan oleh salah satu informan di bawah ini.

"Karena saya punya keyakinan sendiri, saya berdoa minta ampun, saya minta kalau saya diberikan kesembuhan mujizat ya saya sembuh." (KJ, 49 tahun)

Peneliti melihat bahwa pemaknaan keyakinan penderita CKD kepada Tuhan yang diyakininya membuat mereka mampu menerima kenyataan bahwa mereka sedang sakit. Mereka memiliki keyakinan bahwa kehidupan adalah pemberian sehingga dengan apapun yang terjadi atas kehidupannya juga pemberian yang harus diterima dengan senang hati. Pemahaman bahwa penyakit adalah pemberian yang juga harus disyukuri juga terlihat pada salah satu penderita CKD:

"Saya tidak pernah ragu, justru saya bisa baik karena pertolongan Tuhan" (CA, 24 tahun)

\footnotetext{
Pada tahapan penderita CKD melibatkan diri sebagai manusia yang memiliki kuasa selain dirinya. Dalam penyerahan dirinya terhadap sakitnya muncul kepercayaan kuat akan apa yang dia upayakan untuk kesembuhannya. Hal yang sama juga disampaikan oleh penderita CKD yang menjalani prose hemodialisa.
} 
"Waktu divonis gagal ginjal ya takut gak tau obatnya dijalani aja, gak tau penyakit apa itu, sekarang sudah dikasih tau ya dijalani aja seperti orang sehat. Melihat banyak orang yang lebih parah, banyak teman teman yang sudah berpulang, ya Allah terimakasih sudah dikasih umur."(HY,62 tahun)

Pada pernyataan ini dapat dilihat yang mengalami kegelisahan dam ketakutan akan penyakitnya berusaha menaruh harapannya pada Tuhan. Pernyataan ucapan terima kasih atas kehidupan yaitu masih diberikan umur dan kehidupan menunjukkan wujud penerimaan penderita CKD bahwa dirinya tidak bisa disembuhkan namun masih ada yang perlu disyukuri dari keadaan yang sedang dia alami yaitu kenikmatan atas kehidupan dengan proses pengobatan hemodialisa.

Meskipun penderita CKD sudah melalui beberapa tahap mulai dari menjalani pemeriksaan awal pada pelayanan kesehatan di rumah sakit, diagnosa dokter mengenai CKD, diikuti dengan penjelasan mengenai penyakit oleh dokter, pendampingan oleh perawat. Penderita CKD melakukan pengolahan persepsi dan informasi tentang penyakit yang dialaminya secara pribadi. Dengan kelelahannya menghadapi penyakitnya yang tidak bisa disembuhkan, seumur hidup harus bergantung pada alat untuk mencuci darahnya, belum juga kelemahan-kelemahan lain akibat kerusakan ginjal yang dialaminya, rendahnya kadar $\mathrm{Hb}$ dan tinggi nya tekanan darah. Pengalaman ini membuat penderita CKD merasa lelah dan menyerah seperti yang disampaikannya seperti berikut:

'ya dijalanin aja mbak keadaan sekarang ini. Saya pasrah sekarang mbak." (NN, 56 tahun)

"ya pasrah mbak. Mau diapain lagi." (RL, 69 tahun)

"Wis mau ndak mau ya harus cuci darah" (MY, 40 tahun)

"dulu gak tahu. Masih muda sekali saya dan informasi itu gak secanggih sekarang. ngak pernah nyari lagi. Mau dicari apa lagi, wong informasinya sudah mentok itu aja” (DJ, 49 tahun)

Meskipun melalui pengolahan persepsi dan informasi, penderita CKD menangkap bahwa sudah tidak ada lagi yang bisa dilakukan untuk kesembuhan penyakitnya. Keadaan yang pasrah dan menyerah pada apa yang terjadi membuat mereka sekedar menjalani apa yang disarankan oleh dokter selama itu masih bisa dilakukan. Penderita CKD juga mengalami kendala dalam hal pembiayaan dalam proses terapi yang dijalani.

"Waktu saya disuruh cuci darah ya saya bilang waduh uang darimana wong istri saya cuman pembantu. Saya bilang gak usah cuci darah di rumah aja. Saya gak punya apa apa. Semua ditanggung dengan BPJS. Cuma ya berdoa saja."(KJ, 49 tahun)

Penderita CKD mengalami kesulitan dalam hak pembiayaan terapi hemodialisa dan terapi obat-obatan dari dokter. Penderita tetap melakukan hemodialisa sesuai saran dokter karena semua pembiayaan ditanggung oleh Badan Penyelenggaran Jaminan Sosial Kesehatan atau disebut BPJS. Namun begitu penderita CKD tetap mengalami kendala dalam memenuhi terapi yang disarankan, dalam kondisi menjalankan terapi hemodialisa penderita juga tidak jarang mengalami penurunan $\mathrm{Hb}$ yang harus ditangani dengan sejumlah obat yang cukup mahal harganya dan obat lain untuk menurunkan tekanan darah serta beberapa suplemen untuk menunjang kesehatan penderita CKD.

"Biaya ya cari cari sendiri kadang kalau obat disuruh beli gak bisa ya gak beli saya. Jadi 2 bulan sekali masuk RS risiko karena HB turun gak min obat gak bisa beli. Ya sudah risiko sampe sekarang. Kalau memang begini keadaan saya ya bagaimana." (KJ,49 tahun)

Kehidupan penderita sebagai tukang kuli bangunan yang harus bekerja dengan tenaga membuat dirinya tidak berdaya mencari nafkah melakukan kewajibannya sebagai kepala keluarga oleh karena penyakit 
CKD. Keterbatasan kemampuan finansial menjadi salah satu dasar pemikiran penderita CKD dalam memutuskan melaksanakan saran dokter atau hanya berdiam diri di rumah menerima keadaannya dan menjadi pasrah. Keterbatasan finansial pada penderita mendapatkan pencerahan jawaban oleh karena program pemerintah dalam kebijakan pemerintah dalam memberikan layanan kesehatan melalui BPJS sehingga penderita CKD yang disarankan doker untuk melakukan hemodialisa dengan frekuensi antara 2-3 kali dalam seminggu dapat memperoleh fasilitas hemodialisa. Mahalnya terapi hemodialisa berkisar $\mathrm{Rp} 800.000,-$ sampai dengan $\mathrm{Rp} 1.000 .000$,- setiap kali terapi membuat penderita CKD merasa tidak memiliki harapan lagi untuk hidup.

\section{Ketidakpatuhan penatalaksanaan manajemen CKD khususnya diet makanan dan minuman}

Penderita CKD yang menjalani hemodialisa memiliki frekuensi yang berbeda dalam menjalankan terapi hemodialisa anatara 2 hingga 3 kali dalam seminggu. Penderita CKD juga harus menjalani sejumlah pemeriksaan guna memastikan keadaannya tetap baik, seperti menjalani pemeriksaan darah untuk mengetahui jumlah $\mathrm{Hb}$ dan pemeriksaan tekanan darah untuk mengetahui tekanan darah penderita. Penderita CKD cenderung mengalami $\mathrm{Hb}$ rendah karena proses pembentukan sel darah merah mengalami gangguan di dalam ginjal yang mengalami kerusakan. Peningkatan tekanan darah cenderung terjadi pada penderita CKD yang menjalani hemodialisa. Beberapa proses homeostasis dalam tubuh juga terganggu karena kerusakan ginjal, sehingga pada penderita CKD harus menjalani sejumlah diet pada pola makan dan jenis makanannya. Terdapat pantangan sejumlah jenis makanan karena mengandung kalium tinggi seperti buah Belimbing, umbiumbian, sayur berwarna hijau, serta pembatasan cairan masuk berupa minuman maupun makanan. Penderita cenderung menjalani semua anjuran dari dokter dalam menjalani penatalaksanaan manajemen khususnya diet makanan dan minuman pada awal mereka divonis dokter CKD. Dalam perjalanan waktu beberapa penderita CKD merasa mampu mengenali keadaan tubuhnya, sehingga mereka merasa bahwa menjalani diet secara penuh membuat mereka tidak mengalami keseimbangan dalam hidup seperti pendapat informan di bawah ini:

"Ada pantangannya gak boleh makan ini itu, trus saya pernah nurut tenaga saya gak ada saya ngedrop saya, akhirnya saya makan semua tp gak banyak. Dulu saya $90 \mathrm{~kg}$ sekarang $73 \mathrm{~kg}$." (ED, 59 tahun)

"Di rumah juga gak ada pantangan tapi gak banyak, kalau HD ya makannya agak banyak." (AB, 50 tahun)

Penderita CKD memiliki persepsi yang berbeda dengan tenaga medis dan keperawatan. Ada kejenuhan yang penderita CKD alami dalam menjalani kehidupannya dengan sebuah alat hemodialisa pengganti fungsi ginjal mereka yang sudah mengalami kerusakan. Kepekaan penderita CKD dalam merasakan reaksi tubuh atau tanda klinis yang dialami tubuh mereka semakin meningkat sehingga mereka mengukur dengan ukuran apa yang dirasakan. Adanya dilema penderita CKD dalam melaksanakan diet asupan makanan dan minuman, penderita mengetahui dan memahami informasi yang sudah diberikan oleh dokter dan perawat dan semakin mengetahui tanda-tanda klinis yang dirasakan oleh tubuhnya, sehingga mereka mencoba membuat batasan sendiri sesuai dengan apa yang dirasakan. Perawat hemdialisa memiliki pendapat yang berbeda terhadap pantangan asupan makanan dan minuman ini.

"Kadang grup nya mereka itu salah sebenarnya, sembarang dimakan yang diucapkan itu salah." (YN, 39 tahun)

Penderita CKD memiliki kelompok yang anggotanya adalah orang - orang dengan CKD yang menjalani hemodialisa. Salah satu informan dalam penelitian ini seorang perawat hemodialisa di RS William Booth Surabaya mengamati para penderita CKD yang menjalani hemodialisa memiliki respon dalam menghadapi penyakitnya dengan mencari informasi sebanyak mungkin tentang penyakit CKD dan hemodialisa, diwujudkan dengan adanya kelompok atau 
grup penderita CKD yang menjalani hemodialisa dan menerima semua informasi dari sesama rekannya. Menurut perawat YN hal ini sangat wajar dilakukan oleh penderita CKD sebagai bentuk mekanisme koping penderita CKD. Di sinilah peran perawat harus Nampak tetap mendampingi dan memberikan pengertian yang benar terhadap pelanggaran pantangan makanan dan minuman pada penderita CKD dengan memberikan edukasi tentang dampak bila tidak menjaga asupan makanan dan minuman sesuai anjuran dokter.

\section{Dukungan keluarga}

Dukungan keluarga pada penderita CKD yang menjalani hemodialisa sangat besar dampaknya bagi kelangsungan hidup penderita CKD terutama dalam proses penerimaan mereka terhadap sakit yang disandangnya. Keluarga merupakan support sistem bagi penderita CKD dalam menjalani kehidupan penderita CKD. Pendampingan yang penuh dan tulus dari keluarga meningkatkan motivasi penderita CKD untuk terus melanjutkan penatalaksanaan manajemen khususnya hemodialisa.

"Kalo gak ada dukungan dari keluarga ya loyo" (PT, 69 tahun)

"Mama yang paling gak bisa nerima. Suamiku yang sekarang ini suami nyambung. Suami aku yang dulu gak terlalu mendampingi. Aku masuk rumah sakit sendiri, pulang sendiri. Tapi ya saya mikir anak, ya semangatnya karena anak. Tapi kalo lagi jenuh ya, kan manusia ada jenuhnya. Justru dari mama kurang terlalu suport ya. Dari temen- temen SD sampe SMA yang sering nanya kabar. Sering kumpul- kumpul."(MY, 40 tahun)

"Jadi suami trus yang dampingi sekarang." (NN, 56 tahun)

\section{SIMPULAN DAN SARAN Simpulan}

Dalam penelitian ini dapat ditarik beberapa simpulan yaitu:

1. Dalam proses penerimaan kondisi sakitnya, penderita CKD mampu beradaptasi dengan penyakitnya dan menjalani proses penatalaksanaan manajemen terapeutik khususnya hemodialisa.

2. Sejauh ini masih terdapat ketidakpatuhan terhadap penatalaksanaan manajemen terapeutik khususnya diet makanan dan minuman oleh penderita CKD dalam batasan tertentu selama tubuh mereka mampu menerima asupan tersebut.

3. Terdapat beberapa hambatan dalam beradaptasi dengan penyakitnya diantaranya karena masalah kemampuan finansial yang tidak memungkinkan untuk menjalankan penatalaksanaan hemodialisa dan dukungan dari keluarga dirasa kurang oleh penderita CKD.

\section{Saran}

Bagi keluarga agar lebih memiliki waktu dan dukungan untuk mendampingi anggota keluarga yang menderita CKD, karena dukungan keluarga sangat berperan dalam proses adaptasi terhadap sakitnya.

\section{KEPUSTAKAAN}

Alligood, M. R. (2014a) Nursing Theorist and Their Work. 8th edn. Missouri: Elsevier Mosby.

Alligood, M. R. (2014b) Nursing Theorotist and Their Work. eighth. United States of America: Elsevier.

Badan Penelitian dan Pengembangan Kesehatan (BPPK) Kemenkes RI (2013) Riset Kesehatan Dasar. Jakarta.

Bilotta, K. A. J. (2011) Kapita Selekta Penyakit: Dengan Implikasi Keperawatan. 2nd edn. Jakarta: EGC.

Fitriyani, E. N. and Winarti, S. A. (2014) 'Konsep Diri dengan Kejadian Depresi pada Pasien Gagal Ginjal Kronik yang Menjalani Hemodialisa di RSUD Panembahan Senopati Bantul', 2(3), pp. 122-127. Available at: http://ejournal.almaata.ac.id/index.php/ JNKI/article/view/107/106.

Holloway, I. and Wheeler, S. (2010) 
Qualitative Research in Nursing and Healthcare. 3rd edn. United Kingdom: Wiley Blackwell.

Hurst, M. (2015) Belajar Mudah Keperawatan Medikal- Bedah Vol. 1. Edited by Q. Rahma, R. P. Wulandari, and M. T. Iskandar. Jakarta: EGC.

Jos, W. (2016) 'Kualitas Hidup Pasien yang Menjalani Hemodialisis Rutin', eJKI, 4(2), pp. 87-91. doi: 10.23886/ejki.4.6283.87-91.

Kementerian Kesehatan RI (2017) 'Situasi Penyakit Ginjal Kronik', Infodatin: Pusat Data dan Informasi Kementerian Kesehatan RI, March, pp. $1-10$.

Kementrian Kesehatan RI Pusat Data dan Informasi (2017) Infodatin Pusat Data dan Informasi Kementrian Kesehatan: Situasi Penyakit Ginjal Kronis. Jakarta. Available at: file:///F:/YUNI PENELITIAN/Penelitian PDP 2018_Anggaran 2019/gagal ginjal/infodatin ginjal 2017.pdf.

LeMone, P., Burke, K. M. and Bauldoff, G. (2015) Buku Ajar Keperawatan Medikal Bedah. 5th edn. Edited by A. Linda. Jakarta: EGC.

LeMone, P., Burke, K. M. and Bauldoff, G. (2016) Buku Ajar Keperawatan Medikal Bedah. 5 Vol 3. Edited by A. LInda. Jakarta: EGC.

Moleong, L. J. (2014) Metodologi Penelitian Kualitatif. Revisi. Bandung: PT Remaja Rosdakarya.

Pranandari, R. and Supadmi, W. (2015) 'Faktor Risiko Gagal Ginjal Kronik Di Unit Hemodialisis RSUD Wates Kulon Progo', Majalah Farmaseutik, 11(2), pp. 316-320.

Price, S. A. and Wilson, L. M. (2006) Patofisiologi: Konsep Klinis ProsesProses Penyakit. 6th edn. Jakarta: EGC.
Reza, I. F. (2016) 'Implementasi Coping Religious dalam Mengatasi Gangguan Fisik-Psikis-Sosial-Spiritual pada Pasien Gagal Ginjal Kronik', 22(2), pp. 243-280.

Safitri, A. H. and Dewi, D. S. E. (2014) 'KRONIK DI RSU PROF DR . MARGONO SOEKARJO PURWOKERTO DESCRIPTION OF HOPE IN CHRONIC RENAL FAILURE PATIENTS IN', Psycho Idea, 12(1), pp. 47-53.

Streubert, H. J. and Carpenter, D. R. (2011) Qualitative Research in Nursing: Advancing the HUmanistic Imperative. 6th edn. Edited by H. Surrena. Philadelphia: Lippincott Williams and Wilkins.

Suddarth, K. M.-B. B. \& (2013) Brunner Suddart. 12th edn. Edited by E. A. Mardella. Jakarta: EGC.

Suyanto, B. et al. (2011) Metode Penelitian Sosial: Berbagai Alternatif Pendekatan. Edisi Revi. Edited by B. Suyanto and Sutinah. Jakarta: Kencana.

Yasmara, D., Nursiswati and Arafat, R. (eds) (2016) Rencana Asuhan Keperawatan Medikal Bedah: Diagnosis NANDA- 1 2015- 2017 Intervensi NIC Hasil NOC. Jakarta: EGC. 